\title{
Gender-Responsive Sanitation Solutions in Urban India
}

\section{Miriam Hartmann, Suneeta Krishnan, Brent Rowe, Anushah Hossain, and Myles Elledge}

More than 792 million people in India do not have access to improved sanitation. ${ }^{1}$ Although efforts to increase sanitation coverage in rural areas face the principal challenge of changing long-held open defecation behavior, the core challenge in urban areas is addressing inadequate access to and supply of improved sanitation. A growing body of evidence further suggests that women and girls face unique cultural and biological burdens in relation to sanitation. Despite this evidence, systems often continue to compromise the health, safety, and productivity of women, and fail to advance gender equity more broadly. Recent news has also highlighted the potent connection between public sanitation and violence against women in India. ${ }^{2}$ Within this context, gender-responsive sanitation interventions in urban areas have the potential to improve adoption and long-term outcomes for women and their communities through targeted design and implementation.

In this research brief, we provide an overview of recent literature on women and sanitation in urban India. In particular, we consider possible improvements to the design and location of toilet facilities based on articulated needs and current solutions. We also highlight the need for further research evaluating the potential benefits of female-targeted interventions for women and their communities. The issues we consider are context specific, because women's preferences vary across caste, religion, and region. Furthermore, the improvements we discuss respond primarily to existing gender norms. Broader efforts are needed to transform gender norms and meet the dual goals of higher sanitation adoption and better outcomes for women.

\section{Key Recommendations}

- Ensure that toilet design and implementation efforts use a gender-responsive approach to better address the sociocultural and biological needs of women

- Deepen our understanding of the role of gender norms and identities on sanitation technology adoption through further research

- Evaluate the longer term benefits of gender-responsive sanitation solutions on health, safety, productivity, and gender equity

- Evaluate the longer term benefits of gender equity on adoption of sanitation solutions

\section{Designing Sanitation Facilities with Women in Mind} Improving sanitation outcomes involves designing sanitation systems that address women's culturally defined concerns related to privacy and safety and respond to female biological needs such as menstrual hygiene management (MHM) that impact health and mobility. Although few rigorous analyses exist that explore the impact of design changes on adoption, the surveyed qualitative evidence suggests that improvements are warranted and desired.

Gender-Related Design Considerations

- Gender-specific facilities and entrances

- Privacy-minded stall layouts, doors, and sides

- Safe lighting provisions

- Easy maintenance/cleanliness

- Discreet MHM facilities - incinerators, washing stations, pad dispensers

- Smaller, child-friendly seats (to support women's role as caretakers)

Layout design changes can greatly influence perceptions of privacy, security, and comfort. Of these changes, the practice of separating facilities for men and women has most precedence and evident success. ${ }^{3}$ A 1985 World Bank survey of sanitation projects suggested that shared facility design had been a critical deterrent to adoption in past interventions. ${ }^{3}$ More recent case studies from India report that women find both sex-specific stalls and entrances preferable to unisex facilities.,5 Indian nongovernmental organizations (NGOs) Society for the Promotion of Area Resource Centers (SPARC) and Mahila Milan have further recognized the significance of layout configurations on safety and comfort through their consultations with women's groups. In the slums of Mumbai and Pune, standard government community toilets had women's and men's stalls facing each other; other public toilets had entrances facing out to the street.4,6 In both cases, women stated uneasiness with the layout and cited cases of harassment. As a result of these consultations, the NGOs replaced or renovated these facilities by separating entrances and aligning stalls back-to-back to minimize interactions between men and women using the community toilets. Recent quantitative 
analyses from Indian public schools suggest that women's preferences for sex-specific facilities become statistically significant from the age of puberty. One study finds that primary school girls receive significant educational benefitsevidenced by increased enrollment-from the installation of unisex toilet facilities in schools; however, upper-primary school girls receive such benefits only when single-sex facilities are installed in schools, implying a higher need for privacy among pubescent girls. ${ }^{7}$

Other structural design alterations that warrant further inquiry include provisioning for light (whether natural or electrical) and designing openings over stall doors and sides. Some women's self-help groups in India have indicated a preference for stall openings and natural light for brightness and ventilation. ${ }^{4}$ As with all other alterations, however, these must be evaluated within their implementation context, because informal interviews with women in neighboring countries indicate that some past constructions failed to be adopted precisely because women refused to use structures with roofs and side openings that they felt could expose them to men. ${ }^{8}$

Evaluations of public toilets in Delhi suggest that poor maintenance may be a critical deterrent for women..${ }^{9}$ Certain design innovations have the potential to ease the maintenance of public facilities, although cleanliness is often contingent on several factors including funding and accountability. SPARC and Mahila Milan have partially addressed this concern by installing doors that swing both ways in their units to facilitate movement in and out of stalls by maintenance workers. ${ }^{4}$

MHM remains another area for improvement in toilet and facility design. Inadequate MHM provisions pose privacy-related concerns for women and girls and introduce environmental and hygiene-related issues for the entire community. ${ }^{10}$ Specific MHM needs for women may vary depending on caste, religion, or region; broadly, surveys have found disposal, rather than cloth reuse, to be a more common practice for women in urban areas like Delhi, given the limited space and privacy for washing. ${ }^{10}$ Despite the need for disposal facilities, few reportedly exist, and those that do are often unhygienic, without lids or liners. 10

Although greater efforts are being made throughout India to introduce toilet facilities in schools, MHM remains an issue in this setting also. Difficulties associated with the disposal of cloths and napkins have led girls in one school to state that they prefer to miss school during their menses. ${ }^{10}$ Another study of schools across five states in India found that girls often have no choice but to flush pads down the toilet or throw them out the window. ${ }^{10}$ Innovative solutions to disposal problems may be welcomed, depending on culture and context, because girls in one school were willing to adapt to using an incinerator despite some complaints about smoke and smell. ${ }^{10}$
Finally, design innovations that cater to the needs of children may simultaneously address women's needs and reduce their time burdens, given women's usual role as caregivers. Cultural, environmental, and other concerns often lead women to abstain from taking their children to toilets. Many women instead allow their children to openly defecate and consequently become responsible for disposal of the waste.,4,11 Because one common concern is that children could fall into adult-sized latrine drop-holes, SPARC has designed and installed children's toilets at their facilities with resized seats, designated child stalls, and installed handlebars for safe squatting. 4

\section{Identifying Appropriate Locations for New Systems}

Location choices have the potential to lower barriers to access and adoption and thereby decrease health, safety, and privacyrelated risks for women. Very little quantitative research has catalogued these risks in relation to facility location, although such studies are vitally needed to help determine the optimal locations and distribution of facilities near homes, schools, and workplaces. At present, several qualitative studies suggest potential correlations between sanitation location and risk to women.

\section{Gender-Related Location Considerations}

- Proximity of functioning facilities

- Safety measures along possible points of assault

- en route, in stalls, outside facilities

- lighting, formal monitoring systems

- Shorter distances/times traveled

Current data suggest that women are underserved by the low number of toilet facilities available in public spaces; in Ahmedabad, public facilities for men outnumber those for women by nearly $42 \% .12$ Women interviewed from Delhi slums have stated the need for a higher density of women's toilets in their community, where there were reportedly 4 times as many functioning facilities for men as for women. ${ }^{13}$ In the workplace, this lack of access may affect women more acutely than men. Many female service workers interviewed for a study in Bangalore said they felt exposed to shame and harassment when forced to defecate openly because of a lack of facilities. ${ }^{14}$ A study in Chennai found that women without access to toilets would restrict their urination, whereas women with access to toilets who urinated as frequently as men. ${ }^{15}$ Many of the women restricting urination because of lack of access described symptoms associated with urinary tract infections, for which some had been hospitalized. Providing access to sanitation may produce particular benefits to women and girls; a quantitative analysis of Indian public schools found girls' enrollment levels rise at higher rates than boys' in response to latrine installation. ${ }^{7}$ 
For sanitation facilities to serve women appropriately, they must be located at sites that allow for women's safety and other concerns. Nationally, India has made some effort to locate systems according to women's preferences. The rural Total Sanitation Campaign mandates that community facilities be placed in sites that are "acceptable and accessible to women," presumably determined through group consultations. ${ }^{16}$ In urban slums, some NGOs have installed toilets in "central locations" in response to requests from women for informal communal monitoring. ${ }^{4}$ Less attention, however, has been paid to protecting the routes and pathways that individuals must take to arrive at the facilities. One group of women interviewed for a qualitative study of women's sanitation experiences in three Delhi slums identified the majority of verbal and physical sexual harassment incidents as concentrating around the paths leading to sanitation facilities. ${ }^{17} \mathrm{NGO}$ stakeholders from the study also noted women's fears of sexual violence around the toilet blocks themselves, where male drinking and drug use were common, indicating need for further thought on the accessibility and safety of sanitation sites.

Beyond health, safety, productivity, and equity-related implications of access, the relationship between location and women's toilet adoption warrants further exploration. The limited evidence in existing studies indicates that time burden may be an important factor for women in adopting sanitation facilities. One study in Bhopal found that women were half as likely as men to use community toilets and that distance and time were important factors for users. ${ }^{18}$ However, the direct correlation between women's usage and distance has yet to be assessed explicitly.

Ultimately, private toilets may provide the best solution for eliminating location and safety barriers. The success of this solution, however, necessarily depends on the context of implementation. In rural north India, surveys have found that many women from households provided with private government latrines still continue to defecate openly.

Researchers suggest that additional constraints, such as pressure to keep the pit from filling quickly, may affect defecation behavior. ${ }^{19}$

\section{Transforming Gender Norms in Support of Improved Sanitation}

The summarized literature and initiatives, which primarily have sought to improve sanitation systems within the framework of existing gender norms, highlight the relatively constrained positions that women and girls hold in their contexts. To achieve the ultimate goal of full sanitation coverage, it is necessary to consider transforming gender norms through women's empowerment initiatives. A growing body of documentation suggests engaging and supporting women in making sanitation decisions may lead to higher adoption

\section{Women's Empowerment Initiatives}

- Well-structured microcredit programs

- loan disbursement timing and amounts

- Equal gender participation throughout project development

- Gender-conscious payment plans

- monthly family cards or free use

and better health, safety, productivity, and gender equity outcomes for women. ${ }^{20}$ However, the few assessments of these engagement initiatives indicate that initiatives should be careful to appropriately address the social, economic, cultural, and other constraints under which women operate initially.

Targeted financing schemes, such as offering microloans to women, have been deployed by some NGOs to varying degrees of success. The Indian NGO Gramalaya has documented successful WaterCredit programs for women to pay for household toilets, with the loans implemented in a twostage process through neighborhood Women's Self-Help Groups. ${ }^{11}$ One case study of these programs, however, found that only $44 \%$ of the women in Andhra Pradesh opted into the microcredit program, despite widespread fear of assault associated with open defecation and inadequate existing water and sanitation provisions. ${ }^{21}$ Many of the nonparticipating women cited space constraints in their homes as a key barrier to their participation; program managers and evaluators concluded that issues with the loan disbursement plan, which only granted funding after half of the facility had been constructed, resulted in poorer women being left out of the intervention. ${ }^{21}$

Other NGOs, the Bharat Integrated Social Welfare Agency and the Self-Employed Women's Association, combine microloans with sanitation awareness programs to ensure a strong demand base is built prior to initiating construction for private or community toilets. ${ }^{6}$ Such community-centered programs also have the potential to empower women through engagement in the decision-making process. SPARC involves women from early design consultations, to negotiations with government officials, to eventual management of facilities, including maintenance and finances. ${ }^{4}$ These programs enlarge women's roles in project development and seek to invest women in the success of sanitation initiatives. ${ }^{4}$ As women often play integral roles in guiding family sanitation habits, the benefits of targeting women may extend beyond the female population.

Encouraging women to adopt public toilets is often more difficult because of women's concerns about affordability. Standard pay-and-use toilets place particular burdens on women who may not have independent incomes or control over household decision making. Some community toilets address this concern by making use free for women and other 


\section{Research Areas for Considering Gender in Sanitation Design}

- Impact of gender-responsive sanitation interventions on:

- technology adoption;

- health, safety, and productivity; and

gender equity

- Gender-specific needs and concerns of men, boys, and LGBT individuals

- Variations in needs and preferences among women, men, and LGBT individuals by caste, religion, and region

constrained populations such as children and the elderly, although broader initiatives to improve gender equity are essential to ensure that public toilets are accessible to women.

\section{Current Recommendations and Future Research Needs}

In this brief, we introduced a variety of gender-related factors that water, sanitation, and hygiene stakeholders should consider when making design and implementation decisions related to new or existing sanitation systems in urban areas of India. Hitherto, our focus has been on women's and girl's needs, but further investigation of gender and sanitation literature is necessary to identify design and deployment consideration for male and lesbian/gay/bisexual/transgender (LGBT) populations. Further research should also investigate ways to engage men in promoting gender equity in sanitation decision making, access, and utilization. This review also limits discussion to the needs of urban women; future literature reviews could examine variations in women's need across strata such as caste, religion, and region. Sanitation interventions must consider these differences to avoid homogenizing women's interests and to make culturally appropriate design and implementation changes.

This literature review suggests that sanitation facilities have the potential to address women's health, safety, productivity, and gender equity through targeted design and deployment. Existing data suggest that factors such as facility design, location, and empowerment potential must be considered routinely to increase the probability of success, as measured through adoption levels and long-term outcomes for women and the community. The majority of existing research that assesses needs and impacts is qualitative in nature, is based on very small sample sizes, and lacks robust sampling methodologies. Future research should include more rigorous studies (e.g., quantitative surveys, mixed methods research, experimental and quasi-experimental studies) to identify points of concern and measure the relative effects of improvements on user adoption and the longer term economic, health, and other conditions of female, male, and LGBT populations.

\section{References}

1. World Health Organization and UNICEF Joint Monitoring Programme for Water Supply and Sanitation. Progress on drinking water and sanitation. 2014 update. Geneva, Switzerland: WHOUNICEF; 2014 [cited 2015 Jan 26]. Available from: http://www.wssinfo.org/

2. Barry E. Indian premier sets goal of banking access for all. The New York Times. 2014 Aug 15 [cited 2015 Jan 26]. Available from: http://www.nytimes.com/2014/08/16/world/asia/modi-promises-bankaccounts-for-all-families-in-india.html?_r=0

3. Perrett HE. Involving women in sanitation projects. Washington, DC: United Nations Development Programme-World Bank; 1985.

4. Burra S, Patel S, Kerr T. Community-designed, built and managed toilet blocks in Indian cities. Environ Urbanization. 2003 Oct;15(2):11-32.

5. WaterAid India. Tiruchirappalli shows the way: community-municipal corporation-NGO partnership for city-wide pro-poor slums' infrastructure improvement. New Delhi, India: WaterAid India; 2008.

6. Dasra. Squatting rights: access to toilets in urban India. Mumbai, India: Dasra; 2012.

7. Adukia A. Sanitation and education. Cambridge, MA: Harvard University; 2014

8. Nawaz J, Lal S, Raza S, House S. Oxfam experience of providing screened toilet, bathing, and menstruation units in its earthquake response in Pakistan. Gender Dev. 2010;18(1):81-6.

9. Larrousse D, Mathur B, Saunders A. Using the facilities: accessibility of pay and use toilets in Madanpur Khadar resettlement colony of Delhi. UNICEF; 2006 [cited 2015 Jan 26]. Available from: http://www.kcci.org.in/Document\%20Repository/37.\%20pay\%20and\%20use\%20toilets.pdf

10. Kjellen M, Pensulo C, Nordqvist P, Fogde M. Global review of sanitation system trends and interactions with menstrual management practices. Stockholm, Sweden: Stockholm Environment Institute; 2012.

11. Victor BI. India: from alienation to an empowered community-applying a gender mainstreaming approach to a sanitation project, Tamil Nadu. In: United Nations, editor. Gender, water and sanitation case studies on best practices. New York, NY: United Nations; 2006 [cited 2015 Jan 26]. p. 21-2. Available from: http://www.un.org/esa/sustdev/sdissues/water/casestudies_bestpractices.pdf

12. Urban Management Center. City sanitation plan. Ahmedabad. Gujarat, India: Ahmedabad Municipal Corp.; 2012.

13. Sheikh S. Public toilets in Delhi: an emphasis on the facilities for women in slum/resettlement areas. New Delhi, India: Center for Civil Society; 2008.

14. Rajaraman D, Travasso SM, Heymann SJ. A qualitative study of access to sanitation amongst lowincome working women in Bangalore, India. J Water Sanitation Hyg Dev. 2013;3(3):432-40.

15. Diverde H. The sanitary situation and its health effects on women exposed to occupational heat in Chennai, India. Umea, Sweden: Umea University; 2013

16. Pardeshi G. Women in total sanitation campaign: a case study from Yavatmal district, Maharashtra, India. J Hum Ecol. 2009;25(2):79-85

17. Lennon S. Fear and anger: perceptions of risks related to sexual violence against women linked to water and sanitation in Delhi, India. London, UK: UKAid/Sanitation and Hygiene Applied Research for Equity; 2011 [cited 2015 Jan 26]. Available from: http://www.shareresearch.org/LocalResources/ VAW_India.pdf

18. Biran A, Jenkins MW, Dabrase P, Bhagwat I. Patterns and determinants of communal latrine usage in urban poverty pockets in Bhopal, India. Trop Med Int Health. 2011;16(7):854-62.

19. Coffey D, Gupta A, Hathi P, Khurana N, Spears D, Srivastav N, Vyas S. Revealed preference for open defecation: evidence from a new survey in rural north India. Econ Pol Weekly. 2014 Sep 20 [cited 2015 Jan 26];59(38). Available from: http://www.epw.in/special-articles/revealed-preference-opendefecation html

20. Water and Sanitation Program. Gender in water and sanitation. Mainstreaming gender in water and sanitation. Washington, DC: World Bank; 2010

21. Mader P. Attempting the production of public goods though microfinance-the case of water and sanitation. J Infrastruct Dev. 2011;3(2):153-70.

\section{About the Authors}

Miriam A. Hartmann, MPH, is a public health analyst in RTI's Women's Global Health Imperative and is an affiliate of the RTI Global Gender Center.

Suneeta Krishnan, PhD, is a social epidemiologist in RTI's Women's Global Health Imperative and an affiliate of the RTI Global Gender Center. She is also technical lead of RTI's India office.

Brent R. Rowe, MA, is a senior economist in RTI's Center for Environmental, Technology and Energy Economics.

Anushah Hossain is an undergraduate student at the University of California, Berkeley, and an economics research intern in RTI's Center for Environmental, Technology and Energy Economics.

Myles F. Elledge, MPIA, is a senior director in RTI's Center for Technology Applications.

RTI Press Research Briefs and Policy Briefs are scholarly essays on policy, methods, or other topics relevant to RTI areas of research or technical focus.

RTI International, 3040 East Cornwallis Road, PO Box 12194

Research Triangle Park, NC 27709-2194 USA

919.541.6000 rtipress@rti.org www.rti.org

(O2015 Research Triangle Institute. RTI International is a trade name of Research Triangle Institute.

All rights reserved. This brief is protected by copyright. Credit must be provided to the author and source of the document when the content is quoted. Neither the document nor partial or entire reproductions

may be sold without prior written permission from the publisher

http://dx.doi.org/10.3768/rtipress.2015.rb.0009.1502 www.rti.org/rtipress 